\title{
Endocardial fibroelastosis presenting with congenital complete heart block at birth
}

\author{
D H Karunatilaka ${ }^{1}$, G W D S Amaratunga ${ }^{2}$, K D N I Perera ${ }^{2}$
}

Sri Lanka Journal of Child Health, 2000; 29: 95-6

(Key words: Endocardia! Fibroelastosis, congenital complete heart block)

\section{Introduction}

Endocardia! fibroelastosis (EFE) is a rare disorder with a poor prognosis ${ }^{1}$. It is characterised by abnormal thickening of the endocardium of one or both ventricles ${ }^{2}$, often associated with other cardiac abnormalities $^{3}$. It can either present with fetal bradycardia, absent heart sounds in utero or absent heart sounds in the newborn ${ }^{4}$. Both the obstetrician and the paediatrician should be familiar with this condition.

\section{Case Report}

A 27-year-old primipara was admitted to the Teaching Hospital, Colombo South, from the antenatal clinic (ANC) six days after her expected date of delivery. She had failed to attend her last two clinic appointments at the ANC and had been apparently normal during her previous visits.

However, on this occasion, her blood pressure was $130 / 90$ and the fetal heart sounds were inaudible, but she insisted that she could feel regular fetal movements. An ultrasound examination of the abdomen was carried out soon after admission. This confirmed the presence of fetal movements. The fetal heart was found to be enlarged and no other abnormality was reported. There was no evidence of effusion in any of the serous cavities.

A live non-asphyxiated baby boy weighing $2.87 \mathrm{~kg}$ was delivered by Caesarean section. The baby was pink and active at birth, but the heart sounds were inaudible. The rest of the neonatal examination was unremarkable except for absent peripheral pulses. The Apgar score at 1 and 10 minutes were 5 and 7 respectively. This was low owing to the inaudible heart sounds. ECG showed evidence of complete heart block with a rate of 35 beats per minute. Teleradiogram of the chest showed marked cardiomegaly. There were no effusions in the pleural

\footnotetext{
${ }^{1}$ Consultant Paediatrician, Teaching Hospital, Colombo South, ${ }^{2}$ Paediatric Registrar, Teaching Hospital, Colombo South.
}

or pericardial cavities. A 2D echocardiogram done 16 hours after birth revealed gross cardiomegaly with dilatation of the left ventricle The ductus was patent and the left ventricular ejection fraction was $45 \%$.

The haemoglobin $(\mathrm{Hb})$ concentration was $17.2 \mathrm{~g} / \mathrm{dl}$, the total white cell count was $16.2 \times 10^{9} / \mathrm{L}$ with $\mathrm{N}$ $70 \%, \mathrm{~L}-28 \%$ and $\mathrm{M}-2 \%$, ESR was $4 \mathrm{~mm} 1^{\text {st }}$ hour, $\mathrm{PCV}$, platelets, reticuiocyte count, and the serum bilirubin were within the normal range for age. The TORCH screens of both the mother and the baby were normal.

The baby was treated with salbutamol, frusemide and spironolactone at 24 hours of age. Thirty-six hours after starting the above treatment, the heart sounds became audible and the heart rate rose to 50 beats per minute. He fed well and the subsequent weight gain was satisfactory. He was discharged on the same medication.

He remained well on salbutamol and diuretics but continued to have persistent heart block. The subsequent growth was rather slow with both the height and the weight being between $10-25^{\text {th }}$ centiles. He had two severe chest infections complicated by cardiac failure during the next five months and on one such occasion required ventilator support. On the $3^{\text {rd }}$ occasion, in addition to the chest infection complicated by heart failure, paroxysms of pallor with few jerky movements of hands and feet were also noticed. These coincided with multiple ventricular ectopics and ventricular tachyarrhythmia seen on the EGG monitor. His condition deteriorated despite vigorous treatment and he succumbed 3 days later.

Autopsy revealed the persistence of ductus with a grossly dilated heart. The endocardium of both ventricles was markedly thickened with the involvement of the papillary muscles and the chordae tendinae. The myocardium was normal. The microscopic sections done from several areas of both the right and the left ventricle showed a thick layer of collagenous fibrous tissue and elastin fibres confirmed by Vangisen Elastin stain. 


\section{Discussion}

Although no single aetiological factor is directly responsible, EFE has been shown to be associated with tissue carnitine deficiency, twin-to-twin transfusion, carbamazepine therapy and mumps or enteroviral infections in the mother during pregnancy ${ }^{5,6,7,8}$. However, no obvious aetiological factor was found in this mother. Both constricted and dilated forms have been described but many authorities believe that all EFEs are secondary to a reactive process set off by diverse stresses on the myocardium ${ }^{1,9}$. Our patient had the dilated form of the disease. It is also known to be associated with other structural abnormalities such as hypoplastic left heart syndrome and abnormalities of the aortic valve including stenosis ${ }^{3}$. This baby did not have any of the above abnormalities but was found to have a persistent ductus, which was not an abnormality in other reported cases of EFE. Other recognised association described with EFE is a new syndrome of hydrocephalus, cataracts, hydrops fetalis and congenital heart block ${ }^{10,11}$.

This baby who was born with congenital complete heart block complicating EFE, did not show any evidence of hydrops fetalis which is among one of many recognized causes of absent heart sounds at birth ${ }^{4}$.

\section{Conclusions}

Emphasis should be placed on the importance of considering the possibility of congenital complete heart block in cases of fetal bradycardia or absent heart sounds and the necessity to do an ultrasound examination, if the overall clinical picture does not suggest fetal distress or fetal death.

\section{Acknowledgements}

We wish to acknowledge the help given by Dr. Pramod Ranatunge, Resident Cardiologist NHSL, Dr. F Jamaldeen who was involved in the initial evaluation and Dr. Kumudini Wasala Arachchi, Pathologist THCS who did the histopathological studies.

\section{References}

1. Tannouri F, Rypenes F, Peny M 0, Donner C. Fetal endocardial fibroelastosis: ultrasonographic findings in two cases, Journal of Ultrasound in Medicine 1998; 17(1): 63 .
2. Rustico M A, Benettoni A, Bussani R, Maieron A. Early endocardial fibroelastosis and critical aortic stenosis: a case report. Ultra sound in Obstetric and Gynaecology 1995; 5[3]: 202-5.

3. Sharland G K, Chita S K, Fagg N L, Anderson R H. Left ventricular dysfunction in the fetus: relation to aortic valve anomalies and endocardial fibroelastosis. British Heart Journal 1991; 66[6]: 419-24.

4. Herreman G, Sauvaget F, Genereau T. Congenital atrioventricular block and maternal autoimmune diseases. Ann. Med. Interne. Paris 1990; 141 [3]: 2348 .

5. Bennett M J, Hale D E, Pollitt R J, Stanley C A. Endocardial fibroelastosis and primary carnitine deficiency due to defect in the plasma membrane carnitine transporter. Clinical Cardiology 1996; 19[3]: 243-6.

6. Zosmer N, Bajoria R, Weiner E, Vuaghan J. Clinical and echographic features of in-utero cardiac dysfunction in the recipient twin in twin to twin transfusion syndrome. British Heart Journal 1994; 72[1]: 74-9.

7. Nir A, Weintraub Z, Oliven A, Kelener J. Anatomic evidence of spontaneous intrauterine closure of a ventricular septal defect. Paediatric Cardiology 1990; 1[4]: 208-10.

8. Ni J, Bowles N E, Kim Y H, Demmler G. Viral infections of the myocardium in endocardial fibroelastosis. Molecular evidence the role of mumps virus as an etiologic agent. Circulation 1997; 95[1 ]: 133-9.

9. Carceller A M, Maroto E, Fouron J C. Dilated and contracted forms of primary endocardial fibroelastosis: A single fetal disease with two stages of development. British Heart Journal 1990;63[5]:311-3.

10. Devi A S, Eisenfeld L, Uphoff D, Greenstein R. New syndrome of hydrocephalus, endocardial fibroelastosis cataract (HEC syndrome). Am. J Med Genet 1995; 56[1]: 62-6.

11. Carvalho J S, Markiewicz M. Dilated endocardial fibroelastosis: unusual late finding with congenital hydrops. Paediatric Cardiology 1997; 18[5]: 389-91. 